\title{
Há algo de inautêntico em cada original: um brevíssimo estudo sobre a ilusão a partir do filme 0 Melhor Lance, de Giuseppe Tornatore
}

\section{ROGÉRIO DE ALMEIDA}

MARCOS BECCARI

Resumo

Com base no filme $O$ Melhor Lance (LA MIGLIORE OFFERTA, 2013), de Giuseppe Tornatore, este artigo propõe uma reflexão acerca da ilusão do duplo expressa pela dicotomia original-cópia. Após uma breve introdução de como essa dicotomia tornou-se paradigmática no pensamento ocidental, recorremos à filosofia de Clément Rosset para problematizar o mote central do filme: "há sempre algo de autêntico em cada cópia”. Defendemos, por fim, que a ilusão consiste não apenas em transformar uma coisa em duas, mas também na indisposição do iludido em aprovar uma realidade impossível de ser duplicada. 


\title{
There is something inauthentic in each original: a very brief study of the illusion from the movie "The Best Offer" of Giuseppe Tornatore
}

\author{
ROGÉRIO DE ALMEIDA \\ MARCOS BECCARI
}

\begin{abstract}
Based on the film The Best Offer (LA MIGLIORE OFFERTA, 2013), by Giuseppe Tornatore, this article proposes a reflection on the illusion of the double expressed by the original-copy dichotomy. After a brief introduction of how this dichotomy has become paradigmatic in the western thought, we point out the philosophy of Clément Rosset to discuss the central theme of the film: "there is always something authentic in each copy". We argue, finally, that the illusion is not only to transform something into two, but also in the deluded's unwillingness to approve a reality that is impossible to duplicate.
\end{abstract}

Keywords:

Original-copy, illusion, double 


\section{Hay algo inauténtico en cada original: un brevísimo estudio sobre la ilusión a partir de la película "O Melhor Lance" de Giuseppe Tornatore}

\section{ROGÉRIO DE ALMEIDA}

MARCOS BECCARI

\section{Resumen}

Basado en la película "O Melhor Lance" (LA MIGLIORE OFFERTA, 2013), de Giuseppe Tornatore, este artículo propone una reflexión sobre la ilusión del doble, expresada por la dicotomía original-copia. Después de una breve introducción de cómo esa dicotomía se volvió paradigmática en el pensamiento occidental, recurrimos a la filosofía de Clément Rosset para problematizar el tema central de la película: "hay siempre algo auténtico en cada copia". Defendemos, finalmente, que la ilusión no consiste únicamente en transformar una cosa en dos, sino también en la falta de voluntad del engañado para aceptar una realidad imposible de ser duplicada. 


\section{Introdução}

O objetivo deste artigo é tratar do problema do duplo, expresso pela dicotomia original-cópia, em relação à ilusão e ao real. Para pensar tal questão, convocamos o filme $O$ Melhor Lance (La Migliore offerta), do italiano Giuseppe Tornatore (2013), seguindo a linha deleuziana de que os filmes são também obras de pensamento, isto é, de que os cineastas "pensam com imagens-movimento e com imagens-tempo, em vez de conceitos" (DELEUZE, 1985, p. 8) - não se trata, com efeito, de uma análise fílmica, mas sim de uma reflexão filosófica motivada pela obra escolhida.

A questão original-cópia acompanha o pensamento ocidental desde seu surgimento documentado e pode ser equacionado também pelo tema amplamente difundido pela literatura do duplo, que consiste no artifício de tornar dois ou mais o que é um - caso de William Wilson, de Edgar Allan Poe ou O Retrato de Dorian Gray, de Oscar Wilde. Ou o seu reverso: de eleger o original em meio à multiplicidade, golpe que produz, em seu recorte, uma profusão de cópias. Assim, entre Píramo e Tisbe, de Ovídio e Romeu e Julieta, de Shakespeare, gravitam versões e versões com o mesmo leitmotiv da interdição amorosa sucedida por um trágico fim, quase sempre ocasionado por um erro de interpretação. Esteticamente, sabemos, trata-se da mímesis grega, da imitatio latina, da noção de que a arte imita a realidade (natureza) ou mesmo outras obras, constituindo-se a Ilíada e a Odisseia, de Homero, os grandes modelos a serem imitados.

É possível ainda tensionar a questão sob o viés do Romantismo, que institui a lógica da autenticidade, pela qual o gesto do gênio produz obras originais, partindo de uma inspiração mais subjetiva que objetiva - como grava Hegel (1991, p. 227): 
"realizar a perfeição em si própria". Autenticada a originalidade pelos critérios da perfeição, institui-se que as cópias, por mais talento que possa haver em seu engenho, serão sempre de segunda ordem, dependentes da primeira.

Mas o que está na base dessa forma de considerar a relação entre original e cópia data desde Platão. Em Hipias Maior, por exemplo, Hipias diz que belo é uma bela jovem, resposta que é em seguida contestada por Sócrates, que busca justamente a ideia ou o conceito de belo por trás da aparência: "o que procuramos é o por meio do que são belas todas as coisas belas" (PLATÃO, 1980, 294b). Para Hipias, o belo está na aparência, o que singulariza a beleza de cada coisa. Já na República, a arte é a imitação das coisas sensíveis, incapaz de ultrapassar a aparência em direção à realidade (PLATÃO, 1993, X, 598c). Tal perspectiva abre uma fissura entre o real e a aparência e introduz um segundo tema: o da ilusão. Como a aparência não é garantia de autenticidade (o que parece belo pode não sê-lo), a percepção é posta sob suspeita e em suspenso enquanto à razão caberiam os meios de discernir o ilusório do real.

Nesse sentido, como apontou Rosset (2008, p. 24), o tema do duplo não está dissociado ao da ilusão. A estrutura fundamental da ilusão não consiste, assim, na recusa em perceber o real ou na sua confusão com a aparência, como em Platão, mas em desdobrá-lo, isto é, em fazer com que um acontecimento único seja percebido como dois acontecimentos que não coincidem. Assim, a coisa que o iludido "percebe é posta em outro lugar, incapaz de se confundir consigo mesma" (ROSSET, 2008, p. 21, grifo do autor). Portanto, a relação entre original e cópia, quando posta em termos de verdadeiro ou falso, cria a ilusão de uma dupla realidade quando, de fato, só existe uma. A relação, nesse sentido, se dá entre cópias sem original, em que cada coisa, a despeito das imitações e aparências, é radicalmente singular. Em outras palavras, uma coisa é uma coisa e não outra. O que estabelece relações entre as coisas é o gesto interpretativo, dotador de sentidos, produtor de poderes, definidor de repetições. Quando uma coisa é também outra coisa, estamos no território da ilusão, no jogo dos duplos.

Para pensar essa relação entre o duplo e a ilusão, tomaremos como base o filme A Melhor Oferta (2013), de Giuseppe Tornatore e as contribuições filosóficas de Clément Rosset, por meio de uma abordagem hermenêutico-trágica ${ }^{1}$, com o objetivo de compreender como, ao fim e ao cabo, a ilusão, sejamos dela conscientes ou não, se constitui como uma tentativa- ainda que malograda - de se proteger do real. 


\section{Como reconhecer um mesmo quadro pintado duas vezes}

No fundo, todo homem sabe muito bem que não se vive no mundo senão uma vez, na condição de único [als ein Unicum], e que nenhum acaso, por mais estranho que seja, combinará pela segunda vez uma multiplicidade tão diversa neste todo único que se é [...] (NIETZSCHE, 2011, p. 161).

O filme de Giuseppe Tornatore apresenta uma trama complexa, com fios entretecidos numa narrativa de suspense que avança de maneira lenta, convocando o espectador a preencher as lacunas em busca da compreensão da história e da interpretação de seu sentido. Como teorizou Bordwell (1996, p. 33-34),

Quando falta informação, o receptor a infere ou faz suposições. Quando os acontecimentos estão organizados fora da ordem temporal, os receptores tentam colocar essas ocorrências em uma sequência. E as pessoas buscam conexões causais entre os acontecimentos tanto em antecipação como em retrospectiva [...].

Pode-se afirmar que $A$ Melhor Oferta exige do espectador tanto antecipações quanto retrospectivas, uma vez que nem tudo o que se vê é o que parece ser. Assim, um mesmo acontecimento deve ser considerado mais de uma vez, pois embora o acontecimento seja o mesmo, há mais de uma perspectiva no modo de considerá-lo. Eis que aqui operam tanto a hermenêutica quanto a ilusão. A primeira ao esfacelar o fato em prol da interpretação e da reinterpretação, pois elementos novos da trama nos obrigam a reavaliar os anteriores e antecipar os vindouros, ainda que nos frustrem - indício da ilusão. Ao cabo, podemos até acertar o desfecho ou mesmo desconfiar de que o que víamos não era o que parecia ser, mas tal constatação, assim como ocorre com toda a (des)ilusão, só faz confirmar o que de certo modo já sabíamos. É assim que a ilusão opera no filme. Não somente seu protagonista é iludido, mas em certa medida também o somos, ao menos porquanto nos identificamos com seu ponto de vista. Mas para compreendermos esse movimento se faz necessária uma paráfrase, ainda que breve.

O protagonista Virgil Oldman, nome que sugere "velho virgem", é um excêntrico e antissocial leiloeiro de arte que, por nunca ter se relacionado com uma mulher em toda sua vida, guarda secretamente uma valiosa coleção de retratos femini- 
nos. A única pessoa que sabe da existência dessa coleção é seu amigo Billy, cuja amizade é também cultivada secretamente, uma vez que os leilões são manipulados por meio de alguns lances combinados entre os dois. Como um dos maiores especialistas na detecção de obras falsificadas, Virgil Oldman usa de suas credenciais para desvalorizar pinturas que ele mesmo adquirirá por meio de Billy, engordando sua coleção pessoal.

A vida de Oldman muda quando uma mulher misteriosa entra em contato com ele requisitando seus serviços de leiloeiro. Como Claire Ibbetson sofre de agorafobia, jamais sai de sua mansão, não permitindo nem mesmo ser vista por Oldman, que tem de negociar a avaliação da vasta coleção de antiguidades herdada de seus pais primeiramente por meio de contatos telefônicos e posteriormente separados por uma parede. Dessa condição surge a obsessão de Oldman por descobrir quem é a jovem Claire, que há anos vive reclusa do mundo.

Após um lento processo de aproximação, Oldman não apenas consegue vê-la, como também se apaixona por ela e é correspondido, curando-a de sua agorafobia e levando-a para morar junto com ele. É como se Claire fosse uma das raridades que Oldman descobriu sozinho e que, tal como seus retratos femininos, deve ser protegida e cultivada.

Paralelamente, enquanto Oldman dedica-se ao processo de exame das antiguidades de Claire, encontra pelos cômodos da mansão engrenagens que compõem um autômato raro (como o que aparece em A invenção de Hugo Cabret, de Martin Scorsese). Esse autômato é aos poucos reconstruído por Robert, um jovem amigo de Oldman que é hábil na arte de construir engenhocas e seduzir mulheres. É a ele que o "velho virgem" recorre para discutir as melhores estratégias para conquistar Claire.

Fim da história: após voltar de uma viagem, ocasião em que realizou seu último leilão antes de se aposentar, Oldman descobre que sua valiosa coleção de retratos foi roubada por Billy, Robert e Claire - o autômato que é deixado no salão dos quadros explicita a farsa da qual fora vítima. $\mathrm{O}$ boneco repete uma gravação da própria voz de Virgil Oldman: "há sempre algo autêntico em cada uma das falsificações", frase que escreveu em um artigo para defender a ideia de que o falsificador não resiste à tentação de colocar um pouco de si na simulação do trabalho de outro.

Mas o filme não termina aí. Nos dez minutos finais, saltamos no tempo e encontramos Oldman recluso num asilo, relembrando os acontecimentos posteriores à descoberta da far- 
sa. O epílogo não acresce nada que já não soubéssemos, com informações que confirmam o golpe. Mas tal qual um quadro pintado duas vezes, reconhecemos algo de autêntico em sua vida falsamente vivida, o amor. A cena final sintetiza seu drama e se passa no restaurante Night and Day, em Praga, local em que Claire disse ter estado com seu primeiro namorado, um homem mais velho. O restaurante simula o interior de um relógio, com numerosas engrenagens à mostra entre outros tantos relógios. O garçom pergunta a Oldman se ele está sozinho. "Não, estou esperando alguém." São suas palavras finais, de uma ambiguidade incontornável, porque o que ele espera jamais virá. Ou pior: já veio e já se foi, sem nunca ter sido.

\section{A ilusão entre a simulação e o real}

Um pensamento um tanto quanto arraigado na cultura ocidental considera a ilusão como uma simulação do real, a cópia de algo que seria único e autêntico. O real estaria, assim, do lado da verdade, enquanto a cópia seria a expressão do falso, ainda mais quando sua pretensão é ocupar o lugar do autêntico. É esse o pensamento de Oldman - quiçá o modus operandi do mercado das artes -, mas também expressão de certa filosofia platônica - mas não só -, que concebe o real como "modelo" ou a "coisa ela mesma”. Nos termos de Clément Rosset (2004, p. 150): "O brilho da verdade supõe de uma parte um mundo de originais, de outra um mundo de cópias que duplicam mais ou menos habilmente os originais: o brilho da verdade aparece quando se vislumbra o original através de suas cópias” ${ }^{2}$. Essa filosofia considera que o real cotidiano é um duplo cujo sentido só pode ser compreendido a partir de um original.

Embora Oldman, dadas suas habilidades no mercado das artes e dos embustes, fosse a pessoa mais indicada para perceber a ilusão de sua relação com Claire - "até o amor pode ser simulado", alertava-lhe Billy -, ele a cultiva como se fosse autêntica. O filme nos mostra, desde o início, que Oldman é consciente da arbitrariedade que há na distinção entre obras originais e falsas: de modo muito convincente, o leiloeiro fazia um original passar por imitação. Mas sua clareza de percepção é temperada, por outro lado, pelo cultivo de algum mistério, como se houvesse algo que devesse se manter sempre escondido, protegido - o protagonista usa luvas porque possui aversão em experimentar diretamente as coisas.

O que Oldman cultiva, em suma, é um gosto pela simulação e pelo segredo - donde decorre sua aversão pela exposi- 
ção direta, pela explicitação total, pela crueza mundana que é então pressentida como indigesta, duplo de um original posto em outro lugar. Sua coleção de retratos femininos, embora obras de arte originais, funcionam como cópias, ainda que autênticas, de uma mulher original que Oldman perseguiu sem encontrar. É como se ele intuísse nessas mulheres pintadas pelos grandes mestres o perfil da mulher original. Não é de se espantar, portanto, que Virgil perca sua virgindade sexual justamente com Claire, a mulher real que ele descobre em meio às antiguidades e as peças do autômato que, como um quebra-cabeça, Robert remonta. À semelhança do autômato - que reproduz mecanicamente movimentos humanos de acordo com a programação de suas engrenagens - Claire vai sendo construída por Oldman, que vê nela suas próprias características: antissocial, avessa a relacionamentos afetivos, misteriosa, excêntrica etc. Tal qual o autômato, também ela fora programada por Robert para encarnar a mulher original ansiada pelo "velho virgem".

No final das contas, quase tudo era falso: Claire, sua fobia, sua coleção de antiguidades, mas principalmente seu amor. No entanto, se Oldman não percebeu que a situação era simulada, um engodo armado por seus amigos, descobrir a farsa não é suficiente para pôr fim à ilusão. Vítima justamente daquilo que cultivou durante toda a vida, Oldman tenta então resgatar algum aspecto autêntico na simulação vivida (no caso, o restaurante em Praga mencionado por Claire). Nesse sentido, portanto, a ilusão persiste não porque Oldman nega ter sido iludido, mas justamente por reconhecê-la com exatidão e, ao mesmo tempo, não admiti-la.

Admitir a ilusão anularia seu amor por Claire, mas Oldman o preserva como um traço autêntico em meio às falsificações, mantendo-se fiel ao seu pensamento: "Há sempre algo autêntico em cada uma das falsificações". Desse modo, o original, o verdadeiro, permanece intacto, preservado como uma realidade verdadeiramente real, ainda que inacessível. Daí sua resposta ao garçom: "estou esperando alguém”. Oldman - como certa filosofia - está à espera de um sentido a ser descoberto além do real vivido.

Para retomar Rosset (2004, p. 151), o filósofo opõe essa visão à densidade do real, que assinala a

[...] plenitude da realidade cotidiana, ou seja, a unicidade de um mundo que se compõe não de duplos mas sempre de singularidades originais (ainda que sejam "parecidas") e não, 
consequentemente, tendo de prestar contas a algum modelo - filosofia do real, que vê no cotidiano e no banal, mesmo na própria repetição, toda a originalidade do mundo.

Avançando no raciocínio, o que temos é uma originalidade radical de cada objeto existente, anulando, portanto, a possibilidade de cópias. Onde tudo é original (reino da diferença), nada é cópia de nada. Ou, o que é o mesmo dito de outra forma, o que existe é um mundo constituído de cópias sem original (reino da repetição). Tudo copia tudo sem que haja um modelo original para o qual as cópias se voltem. Esse reino das aparências - que é considerado falso pelas filosofias metafísicas - é o único existente sob a perspectiva trágica ${ }^{3}$.

\section{A perspectiva trágica}

Para a perspectiva trágica inaugurada por Nietzsche (1995, p. 118), não há nenhuma dicotomia entre sofrimento e alegria ou qualquer outro par pelo qual a afirmação de um requereria a negação do outro, como original-cópia, verdade-ilusão. O seu "dizer sim sem reservas" à vida inclui o sofrimento, isto é, concebe que a vontade de viver se manifesta diante do caráter trágico da existência. Trágico aqui entendido como "a afirmação da incapacidade humana para reconhecer ou constituir uma natureza" (ROSSET, 1989a, p. 104). Ou, em outras palavras, não há falta de ser, mas "plenitude de ser", isto é, nada falta ao homem (ROSSET, 1989a, p. 49), cuja existência é plena, ainda que efêmera, transitória e insignificante.

Assim, a filosofia trágica se diferencia das demais pelo que se propõe: atém-se antes à inocência e crueldade do real que à sua bondade ou culpabilidade; enxerga acaso e artifício em vez de necessidade e liberdade na natureza; opta pela lucidez, ainda que insignificante, à ilusão das ideias e ideologias. Enfim, a filosofia trágica opõe-se aos objetivos da metafísica, pois entende que a dicotomia entre original e cópia ou necessidade e liberdade não expressam nenhum aspecto do real, constituindo-se, ao contrário, como estratégias para evitá-lo (HIERRO, 2001, p. 24).

Virgil Oldman encarna justamente essa perspectiva filosófica que, diante do trágico, isto é, diante do real cru, decide buscar a realidade em outro lugar, de preferência onde nada existe. Sua ilusão consiste na incapacidade de admitir que o real banal e cotidiano é suficiente e, portanto, basta. Para ele, ocorre como no mercado das artes: um quadro original é único, valiosíssimo 
e deve ser escondido da vida ordinária, repleta de cópias e obras sem autenticidade. Aliás, é essa a crítica endereçada a seu amigo Billy: sua arte não tem autenticidade. $O$ engodo armado por Billy, pelo qual rouba todos os quadros de Oldman, além do valor financeiro em questão, tem o potencial de redimi-lo de seu ressentimento: um golpe autêntico, ainda que tenha se valido de numerosas repetições e falsidades.

No entanto, a dor maior de Oldman não parece ser a perda financeira causada pelo golpe, tanto que o assimila e investiga seus detalhes, mas a perda da ilusão e seu retorno ao real real que ele não admite. Em outras palavras, ele confronta o trágico, mas não o afirma. Assim, ele compreende bem que perdeu sua coleção de quadros, que Billy, Robert e Claire armaram uma trama que o enredou, que a mulher pela qual ele se apaixonou jamais existiu etc., mas não aceita que o amor não tenha valor, que não exista uma realidade superior a essa da aparência, da cotidianidade, da crueza. ${ }^{4}$

Assim, se de certo modo não há como responsabilizar Oldman (o velho homem experiente) pela ilusão de acreditar no amor de Claire - afinal em matéria de amor ele era "virgem" -, é possível, por outro lado, compreender sua recusa em admitir, não que foi enganado, mas que o amor era também uma ilusão. É por isso que Oldman, depois de tudo compreendido, vai a Praga acreditando na possibilidade de reencontrá-la. Mas reencontrar quem, se Claire nunca existiu? Se ela nunca passou de uma cópia de um original inexistente, idealizado por Oldman e cultivado por meio dos retratos femininos de sua coleção de arte?

Dir-se-ia que um programador divino e universal, a menos que se trate apenas do acaso das coisas, como sugere Epicuro, cometeu aqui um erro de base, endereçando uma informação confidencial a um terminal incapaz de recebê-la, de dominá-la e de integrá-la a seu próprio programa: revelando ao homem uma verdade que ele é incapaz de admitir, mas também, e infelizmente, muito capaz de entender (ROSSET, 1989b, p. 23).

Esse dado trágico - o homem está capacitado a entender, mas não a admitir - sintetiza o comportamento de Oldman. Ele compreende a ilusão da qual foi vítima, mas não a aceita. Isso faz com que a ilusão não se desfaça por completo. Seu retorno ao real é, assim, provisório. Desfeita a ilusão, restaria a realidade: Billy o roubou, Robert agiu premeditadamente, o autômato funcionou como uma isca para seu interesse de 
colecionador e Claire jamais sofreu de agorafobia, jamais herdou antiguidades e, sobretudo, jamais esteve apaixonada por Oldman. Mas não é assim que ele percebe. Incapaz de admitir a última constatação, deixa-a em suspenso, como "algo autêntico" no conjunto de falsidades que o envolveu.

Conquanto se trate de um caso de ilusão, sua efetivação ocorre por meio do duplo. Oldman duplica a realidade para preservar o que não é capaz de admitir. Assim, ilusão desfeita, Oldman encara a falsidade de todas as relações empreendidas com Billy e Robert. A realidade se desnuda. Fora vítima de um golpe. E embora perceba claramente que o mesmo tenha se dado com Claire, é como se a destacasse do real e a colocasse em outro lugar, um lugar em que ainda possa amá-la. Efetivamente, Oldman ainda ama Claire. Mas como pode amar uma mulher que não só não existe como jamais existiu? Há, portanto, uma Claire real, jovem e bonita, que simulou amá-lo para descobrir o segredo do cofre onde guardava sua coleção de arte para roubá-la. E há outra Claire, a que ele amou, e que não existe nem nunca existiu. A ilusão de Oldman é considerar essa Claire inexistente como sendo a original, da qual a que existe não passa de mera cópia.

\section{O que (não) se vê e o que (não) é visto}

Enxergamos as coisas não como elas poderiam ou deveriam ser, tampouco como elas "sempre foram" (ilusão de identidade), mas somente como elas aparentam ser em determinado momento. Pois não é o mundo que se adapta ao sentido que damos a ele, mas o inverso: nosso olhar é que se adapta ao que nos é dado a ver. Não se trata de um modelo de como o mundo deve ser enxergado; ao contrário, trata-se de reconhecer que, se os olhares são múltiplos e diferentes, o que vemos é um "conjunto disjuntivo" de impressões disjuntas e divergentes.

Noutras palavras, o mundo que vemos é sempre o mesmo, mas o que é visto nunca é um mesmo mundo. Difícil é assimilar a relação de equivalência, em vez de sobreposição, entre o mundo "mesmo" e a pluralidade que o compõe. Porque uma vez constatada a diferença de olhares sobre o mundo mesmo, corremos o risco de querer "limpar" o real das ilusões que o velam e, com isso, anular o próprio real - jogar fora o bebê com a água suja do banho. Tal empreitada culmina na intenção clássica da "representação": querer extrair aspectos coerentes e unívocos em meio às inconsistências que não cessamos de ver no mundo. 
De modo contrário, é possível afirmar que não há o que se ver "por trás" das coisas vistas. O mundo é, assim, aparência de mundo, traduzido por sentidos que o expressam pluralmente e por meio dos quais nos inserimos nele. Em suma, o espaço das aparências não é outro senão o lugar onde se encontra o real.

Se o mundo é dado pela pluralidade de olhares, aparências e sentidos, em contrapartida a ilusão ocorre pela adesão a um único olhar pretensamente erigido como portador de um acesso "neutro" à realidade. E ao negar o caráter ilusório da neutralidade tida por verdadeira, a ilusão aposta na dissolução de todas as ilusões, isto é, todas as outras visões que dela diferem.

A estrutura fundamental da ilusão consiste, portanto, em transformar uma coisa em duas, exatamente como a técnica do ilusionista que, enquanto se ocupa com o truque, dirige o olhar do espectador para outro lugar, para lá onde nada acontece. As coisas ocorrem como se fossem independentes, sem que, no entanto, se desvinculem efetivamente. Por isso a figura do autômato, em $O$ Melhor Lance, é uma referência constante: uma máquina que simula um raciocínio autônomo, ocultando as "engrenagens" de um ventríloquo invisível.

É explícita, no filme, a associação do autômato com a anã que registra tudo o que vê: nada passa despercebido por ela (sua memória é como uma calculadora interminável) e, contudo, ela é incapaz de assimilar o que se passa ao seu redor. Ou seja, ela faz apenas o que se espera que ela faça, porque a função do autômato é, em última instância, agir sem levantar suspeitas, passando despercebido, tal como os replicantes da ficção científica.

Aos olhos de Oldman, no entanto, o mecanismo da ilusão sempre esteve não apenas desvendado, mas também disponível e facilmente forjável (como de fato o faz em seus leilões, junto a seu cúmplice). Ao mesmo tempo, e talvez justamente por isso, o leiloeiro cultiva suas próprias ilusões num lugar secreto - como a sala dos retratos femininos -, lá onde estariam protegidas de qualquer desilusão.

De maneira esquemática, com efeito, podemos pensar em dois níveis de ilusão: a de "primeiro grau", que é irrefletida, pautada no olhar distraído ou ingênuo; e a de "segundo grau", que persiste no olhar não ingênuo, consciente das ilusões. Se na ilusão de primeiro grau não há o reconhecimento da ilusão mesma, na de segundo grau o reconhecimento já ocorreu, mas de tal modo que a ilusão instala-se definitivamente à medida que reconhece muito bem o mecanismo ilusório, tentando então a todo custo proteger-se da desilusão. Em ou- 
tras palavras, a ilusão de segundo grau mantém-se ilusória por medo de ser ilusória.

O mecanismo desse segundo grau da ilusão consiste na autoproteção, geralmente atrelada a uma aura de lucidez em relação às ameaças ilusórias das quais se julga estar definitivamente livre. No caso de Oldman, sua lucidez consiste em saber que não há como provar a originalidade das coisas sem haver um argumento, um critério e uma garantia externamente acrescentados ao objeto de juízo. Ao mesmo tempo, seu maior receio é o de ver expostos seus segredos, ou seja, a parte autêntica de sua vida que ele guarda a sete chaves.

Apesar de saber que tudo pode ser simulado, inclusive o amor, Oldman preserva aquilo que ele mesmo simula como algo autêntico e elevado: suas superstições, seu gosto artístico apurado e sua obsessão por retratos femininos. De fato, Oldman é um homem que cultiva ilusões. O que lhe tornou vulnerável a iludir-se em definitivo, contudo, foi cair na armadilha arquitetada por Billy, que o fez acreditar que finalmente encontrou sua mulher ideal: uma que vive em segredo, intocável, escondida do mundo.

Eis a isca perfeita: a possibilidade de suas pequenas ilusões deixarem de ser meramente simuladas (cópias) para tornarem-se promessas, neste caso por meio de um amor verdadeiro (original). Oldman cai no golpe - eis aqui o seu pior lance - por ter dado crédito desmedido a suas próprias ilusões, que antes eram apenas cultivadas em segredo e depois lhe foram literalmente roubadas. Vendo a si próprio como objeto de manipulação, o ilusionista dos leilões perde por completo sua lucidez, tornando-se o autômato que não sabe da encenação da qual faz parte - exatamente como a anã, que não obstante chama-se Claire e é proprietária da casa onde toda a encenação foi articulada.

\section{Conclusão}

Encontramos no filme de Tornatore um material rico para estudar a relação entre o duplo e a ilusão - objetivo a que nos propusemos neste artigo. Como obras que pensam, os filmes possibilitam levantar questões de pensamento sem operar com conceitos, mas por meio de imagens em movimento materializadas no encadeamento temporal próprio das narrativas. Desse modo, o filme selecionado - O Melhor Lance - não se constituiu como objeto a ser analisado; não se buscou uma leitura crítica, histórica ou estética da película em questão; 
também não objetivamos situá-lo no conjunto da filmografia do cineasta italiano ou mesmo interpretá-lo à luz de uma dada teoria. Enfim, não se empregou uma metodologia para análise do filme, mas fizemos do próprio filme um método hermenêutico para pensarmos/interpretarmos/analisarmos o problema posto em questão, isto é, o modo como o duplo e a ilusão se relacionam à luz da filosofia trágica.

Desse modo, há uma imagem no filme que é bastante salutar para sintetizar o itinerário percorrido: Oldman no asilo preso a uma máquina de terapia que gira o corpo tridimensionalmente no espaço. Com os braços e pernas abertos, não há como não relacioná-lo ao homem vitruviano de Leonardo Da Vinci. No entanto, o homem contemporâneo, distintamente do homem moderno, não ocupa posição central, medida de todas as coisas, mas gira aleatoriamente no espaço, ora de lado, ora de cabeça para baixo, sem referência, como que a indicar que as medidas são todas relativas. Oldman é, portanto, a medida de suas próprias ilusões.

Ilusões, no entanto, que estão menos ligadas ao golpe do qual fora vítima que à sua persistência em não admiti-las. Embora não lhe falte discernimento para compreender a trama na qual foi urdido, falta-lhe disposição para aprovar a realidade vivida. Assim, Oldman preserva a ilusão de um amor original; não se dá conta de que, como qualquer outra relação - a de amizade, por exemplo -, pode ser simulado. $\mathrm{Ou}$, mesmo quando experimentado, como o foi de sua parte, apresenta algo de inautêntico. Algo é sempre copiado nas relações afetivas. Oldman não "copiou" Claire de seus retratos femininos? Não "copiou” Robert ao seguir seus "conselhos" para seduzir a jovem desconhecida? A própria Claire não era uma cópia de suas excentricidades? Não partilhava ela também da busca por uma relação original, autêntica, que fosse única e verdadeira? Enfim, ilusões.

Desse modo, é possível advertir que as cópias vividas na realidade são cópias sem original, ou melhor, são sempre originais, ainda que não autênticas, dada a radical singularidade de toda existência e o conjunto assinalável das repetições. $\mathrm{O}$ amor, que é sempre único na vivência subjetiva de cada qual, repete-se ad nauseam e mutatis mutantis por todas as culturas humanas. A tese do filme - se pudéssemos concluir a investigação sintetizando uma - seria justamente o contrário da defendida por Oldman: há algo de inautêntico em cada original. Inautêntico aqui no sentido de repetir/imitar. Tese que restitui o duplo à singularidade - não teríamos, portanto, 
duas realidades: esta, cotidiana, da ordem das cópias; aquela, atingível sob certas condições, original e modelar. Tese também que, se não condena propriamente a ilusão - quem não estaria vulnerável aos caprichos dos desejos? -, condena os artifícios que não aprovam o real. Essa aprovação incondicional da realidade, embora inautêntica - porque repetida, ainda que por uma minoria, desde tempos imemoriais - é o que há de mais original na existência, justamente por advertir que a existência é impossível de ser duplicada.

\section{NOTAS}

1. “[...] se tudo pode ser interpretado, é precisamente porque não há o que ser interpretado - sendo um dos aspectos do trágico 'o que se furta a toda tentativa de interpretação' [Rosset]. [...] Com efeito, por 'hermenêutica trágica' devemos entender apenas uma hermenêutica que, como a de Ricoeur, não pressupõe um conteúdo específico a ser interpretado, mas que, em vez disso, encare o compreender como um modo-de-ser" (BECCARI, 2015, p. 101).

2. Todas as citações desta obra, no original em francês, foram traduzidas por nós.

3. “O mundo 'aparente' é o único. $\mathrm{O}$ 'mundo verdadeiro' é apenas acrescentado mendazmente” (NIETZSCHE, 2006, III, §2, p. 26).

4. "Cruor, de onde deriva crudelis (cruel) assim como crudus (cru, não digerido, indigesto) designa a carne escorchada e ensanguentada: ou seja, a coisa mesma privada de seus ornamentos ou acompanhamentos ordinários, no presente caso a pele, e reduzida assim à sua única realidade, tão sangrenta quanto indigesta. Assim, a realidade é cruel - e indigesta - a partir do momento em que a despojamos de tudo o que não é ela para considerá-la apenas em si-mesma [...]" (ROSSET, 1989b, p. 18).

\section{Referências}

BECCARI, Marcos. Articulações simbólicas: uma filosofia do design sob o prisma de uma hermenêutica trágica. 2015. Tese (Doutorado) - Faculdade de Educação da Universidade de São Paulo, São Paulo, 2015.

BORDWELL, David. La narración en el cine de ficción. Barcelona, Buenos Aires, México: Paidós, 1996.

DELEUZE, Gilles. Cinema: imagem-movimento. São Paulo: Brasiliense, 1985 .

HEGEL, Georg Wilhelm Friedrich. Estética: a ideia e o ideal. Estética: o belo artístico ou o ideal. Tradução Orlando Vitorino. 5. ed.. São Paulo: Nova Cultural, 1991. (Coleção Os Pensadores).

HIERRO, Rafael Del. El saber trágico: de Nietzsche a Rosset. Madrid: Ediciones del Laberinto, 2001.

NIETZSCHE, Friedrich. "III Consideração Intempestiva". In: . Escritos sobre educação. Tradução Noéli Correia de 
Melo Sobrinho. São Paulo: Ed. Loyola, 2011. . Ecce homo. Como alguém se torna o que é. Tradução Paulo César de Souza. São Paulo: Companhia das Letras, 1995.

.Crepúsculo dos ídolos: como se filosofa com o martelo. São Paulo: Companhia das Letras, 2006.

PERNIOLA, Mario. Desgostos: novas tendências estéticas. Tradução Davi Pessoa Carneiro. Florianópolis: Editora da UFSC, 2010.

PLATÃO. Hipias Maior. Tradução Carlos Alberto Nunes. Belém: Editora Universidade Federal do Pará, 1980.

. A República. Tradução Maria Helena da Rocha Pereira. Lisboa: Fundação Calouste Gulbenkian, 1993.

ROSSET, Clément. A lógica do pior: elementos para uma filosofia trágica. Tradução de Fernando J. F. Ribeiro e Ivana Bentes. Rio de Janeiro: Espaço e Tempo, 1989a.

.Princípio de Crueldade. Tradução José Thomaz Brum.

Rio de Janeiro, Rocco, 1989b.

. Le réel: traité de l'idiotie. Paris: Les Éditions de Minuit, 2004.

. O Real e seu duplo: ensaio sobre a ilusão. Tradução José Thomaz Brum. Rio de Janeiro: José Olympio, 2008.

\section{Referência Fílmica}

LA MIGLIORE OFFERTA. Giuseppe Tornatore. Itália: Paco Cinematografica/Warner Bros., 2013.

Recebido em: 25/02/16

Aceito em: 16/05/16 
ROGÉRIO DE ALMEIDA

rogerioa@usp.br

Professor na Faculdade de Educação da Universidade de São Paulo (USP). Graduado em Letras e doutor em Educação pela USP. Trabalha com temas ligados à Antropologia do Imaginário, à Pedagogia da Escolha e à Filosofia Trágica. Autor de, entre outros, $O$ criador de mitos: imaginário e educação em Fernando Pessoa (Educ, 2011) e O imaginário trágico de Machado de Assis: elementos para uma pedagogia da escolha (Képos, 2015).

\section{MARCOS BECCARI}

contato@marcosbeccari.com

Professor no Departamento de Design da Universidade Federal do Paraná (UFPR). Doutor em Educação pela Universidade de São Paulo (USP), designer gráfico e mestre em Design pela UFPR. Trabalha com temas ligados à Filosofia Trágica, Hermenêutica, Estética e Visualidade. Autor de Articulações Simbólicas: uma nova filosofia do design (2ab, no prelo) e coautor de Existe design? Indagações filosóficas em três vozes (2ab, 2013). 